\title{
Multiple criteria decision making with life cycle assessment for material selection of composites
}

\author{
A. S. Milani ${ }^{*}$ C. Eskicioglu, K. Robles, K. Bujun, H. Hosseini-Nasab \\ School of Engineering, University of British Columbia, Okanagan Campus, Kelowna, BC V1V 1V7, Canada
}

Received 25 January 2011; accepted in revised form 25 June 2011

\begin{abstract}
With the advancement of interdisciplinary approaches in today's modern engineering, current efforts in optimal design of composites include seeking material selection protocols that can (1) simultaneously consider a series of mechan$\mathrm{ical} /$ electrical/chemical cost criteria over a set of alternative material options, and (2) closely take into account environmental aspects of final products including recycling and end-of-life disposal options. In this paper, in addition to a review of some recent experimental and methodological advances in the above areas, a new application of multiple criteria decision making (MCDM) is presented to deal with decision conflicts often seen among design criteria in composite material selection with the help of life cycle assessment (LCA). To show the application, an illustrative case study on a plastic gear material selection is conducted where the cost, mechanical and thermal properties along with environmental impact criteria are to be satisfied simultaneously. A pure plastic gear is compared to a Polyethylene terephthalate (PET)/aluminum-powder composite alternative. Results suggest that simple MCDM models, including a signal-to-noise measure adapted to MCDM in the same case study, can be used to explore both trade-offs and design break-even points in large decision spaces as the decision maker's perspective over environmental, material performance and cost attributes change during the design process. More advanced topics including the account of material data uncertainties are addressed.
\end{abstract}

Keywords: polymer composites, material selection, multiple criteria decision making, life cycle assessment, sensitivity analysis

\section{Introduction}

Material selection is crucial in many engineering projects as it can determine the durability, cost, and manufacturability of final products. In addition, due to increasing regulations by government organizations, manufactures are required to minimize environmental impacts of their processes and products. In fact, material selection can be pivotal for environmental concerns as recyclability and/or the endof-life disposal methods vary from one choice of material to another. In today's integrated design processes (IDP), a systematic selection of the best material for a given application begins with indentifying multiple mechanical/electrical/chemical/thermal properties, environmental impact factors, and life cycle costs of candidate materials (Figure 1). In essence, IDP requires design teams from different disciplines to work together from the project onset to develop solutions that have multiple benefits. When multiple criteria from different disciplines are to be satisfied in a material selection problem, however, complexities often rise with regards to criteria conflicts and/or the importance of each criteria/discipline. Also, expert knowledge becomes fundamentally important to define correct indices within each discipline. For example, the leaf spring/ beam of a wing spar may be desired to be light and at the same time strong to support a given bending load without deflecting excessively. The beam material selection problem is then considered as an opti-

\footnotetext{
${ }^{*}$ Corresponding author, e-mail: abbas.milani@ubc.ca
}

(c) BME-PT 


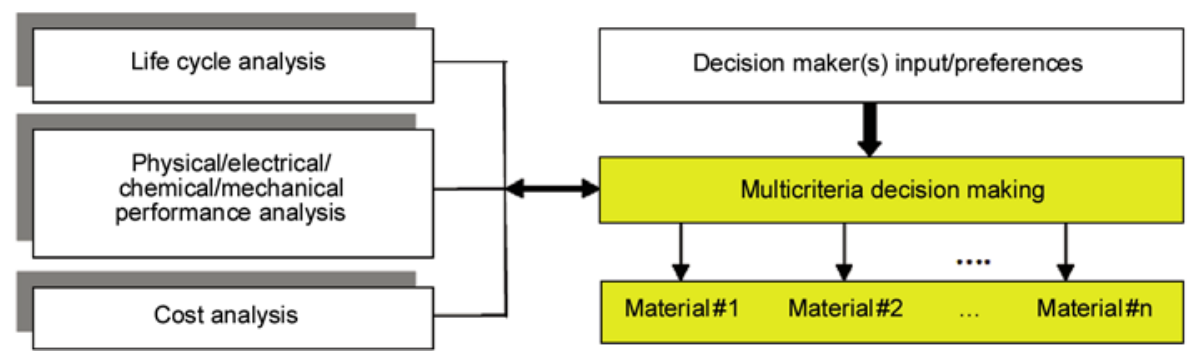

Figure 1. Schematic of material selection in an integrated design process

mization problem where the density, $\rho$, should be low while the elastic modulus, $E$, should be high enough to bear the load without exceeding a given maximum allowable deflection. It maybe assumed that the beam's length and width are constant and only its thickness can vary to accommodate the design objectives. The simultaneous formulation of the beam's mass and elastic deflection as a function of the thickness gives a material performance index (i.e., a combination/ratio of the material properties) as $E^{1 / 3} / \rho$. This index should be maximized during the material selection process; see [1] for more theoretical details. If during decision-making the mechanical design group in the project uses the density and stiffness as individual material properties (and not as a ratio as defined above), less accurate or not application-specific results would be obtained.

A number of recent experimental studies and selection methods have been reported in the literature to highlight the above multi-disciplinary nature of composite material and product selection in IDP's. Among these studies, those with a focus on environmental performance of composites are reviewed in Section 2. Research directions in relation to current efforts in improving the recycling techniques of composites are also addressed (Section 3). Next, an illustrative case study is presented in Section 4 on gear material selection with an emphasis on the application of multiple criteria optimization methods and their appropriateness to explore trade-offs and break-even design points when cost, environmental and mechanical factors are simultaneously taken into account. A new signal-to-noise $(\mathrm{S} / \mathrm{N})$ concept in MCDM is also adapted in the same case study. Concluding remarks are included in Section 5.

\section{Composite design and material selection with environmental considerations:} A review

In recent years, there has been an increasing trend in the use of composite materials primarily in the aerospace and transportation industries. In comparison to traditional materials, composites offer higher strength to weight ratios, non-corrosive properties, dimensional stability and good conformability. To give a few examples, percentage weight of composites has increased from 3\% in Airbus A320 to over $20 \%$ in A380. Similarly, Boeing uses over $50 \%$ of composite materials in its 787 aircraft (for more specific examples of current applications of fiberreinforced composites in the aircraft industry, see the study [2]). Similarly, composite materials have played key roles in reducing the magnetic, acoustic, hydrodynamic, radar, thermal signatures, as well as increasing payload, top speed, and operation range in marine structures [3].

Next to the above-mentioned superior physical and mechanical properties, recent studies show that composites can increase savings of emissions to the environment, in particular in transport industries, when compared to more traditional structural materials such as aluminum [4]. In air transport, emissions can be more environmentally damaging than those at ground level due to increased interaction of structures with gases at high altitudes. Scelsi et al. [4] through a life cycle assessment (LCA) analysis on a set of actual aerospace components showed that commercial fiber-reinforced composites such as GLARE yield substantial reductions in overall environmental impact during the use stage (e.g., $240000 \mathrm{~km}$ of flight distance). This is despite the fact that composites are more energy intensive to manufacture and more difficult to dispose com- 
pared to traditional materials such as aluminum. To address the latter gap/difficulty, numerous research groups have launched state-of-the-art projects to develop more environmentally friendly composites such as natural fiber-reinforced polymers.

Holbery and Houston [5] describe applications of natural-fiber-reinforced polymer composites in automotive components. Their work suggested that natural fibers in composites yield high quality composite products while minimizing environmental impacts. Namely, fibers such as flax, hemp, and kenaf were tested and compared to more traditional composites (such as glass fibers) to demonstrate the competence of the natural counterparts. Nonetheless, it was concluded that there still exist challenges to overcome in this field, including moisture stability, fiber-polymer interface compatibility, and consistency of fibers. Mechanical properties and biodegradability of green composites (as linked to environmental factors) have also been studied experimentally by Shibata et al. [6]. They scrutinized a set of composite laminates composed of regenerated cellulose (lyocell) fabric and three types of biodegradable polyesters [poly(3-hydroxybutyrate-co-3hydroxyvarelate) (PHBV), poly(butylene succinate) (PBS), and poly(lactic acid) (PLA)]. The polyester/ lyocell composite specimens were made of compression molding and examined for the effect of natural fiber content on their tensile moduli and strengths, as well as Izod impact resistance. In addition, biodegradability of the specimens were compared via a 120 day soil viral test and the order of highest to lowest biodegradable polyester/lyocell composite was found to be: PHBV $>$ PLA $>$ PBS. Regarding mechanical properties, at the same fiber content the order of candidate materials was as follows. Tensile moduli of PLA composites was higher than those of PBS and PHBV composites, whereas PBS composites had higher tensile strength than PHBV and PLA specimens. In view of MCDM, a clear indication of these results is that for each chosen design/ material selection criterion, a different top candidate can be nominated (i.e., the presence of conflicting criteria in choosing a final material).

Netravali et al. [7] presented a set of experiments intended to compare the mechanical performance of environmentally friendly (green) composites to common synthetic reinforced plastics. A modified soy protein based matrix was used by creating an 'inter- penetrating network like (IPN-like) resin' with mechanical properties comparable to those of commonly used epoxy resin. The IPN-like soy proteinbased resin was further reinforced using nano-clay and microfibrillated cellulose. Different fibers including high strength liquid crystalline cellulose, aramid and E-glass fibers in the modified resin were used and the ensuing tensile and flexural strengths of composites were tested. It was demonstrated that the green fiber alternative was very competent. Although the soy-based materials and cellulose were fully biodegradable, challenges such as consistent quality and water resistance remained yet to be overcome for full applications of green composites.

A formal LCA of biofibers as reinforcement in plastic transport pallets has been conducted by Corbiere-Nicollier et al. [8]. They performed LCA in order to analyze the possibility of using China's reed (CR) fiber as a replacement for glass fiber (GF). The analysis considered the entire life cycle of the two candidate materials including energy use, efficiency of transportation, and disposal waste phase. A comparison of emissions of pollutants into air, soil and water due the life cycle stages of the two materials was made (Table 1 only shows the emissions to the air as sample results). It was concluded that CR fiber could be an excellent alternative given that its lifetime is greater than the required minimum three years and over this period a notable effect on the reduction of polypropylene content, reduction of energy to create fibers, and improved fuel efficiency in transportation due to the use of lighter material are achieved. The $\mathrm{CO}_{2}$ emission from GF pallet was $33.1 \mathrm{~kg}$ more than $\mathrm{CR}$ pallet.

Katz [9] compared the environmental load of fiberreinforced polymer (FRP) reinforced pavements to that of steel reinforced pavement. The study accounted for the entire life cycle of the pavements, from obtaining the material resources to disposal. The analysis was carried out using the Eco-Indicator $99^{\circ}$ : the environmental performance indicator method for LCA and ecodesign. The study divided the life cycle of a given pavement reinforcement candidate to three stages: erection, maintenance, and disposal (Table 2). Three types of carbon FRP's were tested and they all showed a lower environmental burden than the steel alternative in the main- 
tenance stage, mainly due to the reduced cement content. However, at the disposal stage, the environmental load of the steel reinforced pavement, as can be seen in Table 2, was found to be lower than that of FRP reinforced pavements (i.e., again an example of a local criteria conflict in choosing the final/optimum material).

Table 1. Comparison of emissions of pollutants into air for glass fiber and China reed pallets [8]

\begin{tabular}{|l|l|c|c|}
\hline \multicolumn{1}{|c|}{ Substance } & Unit & GF pallet & CR pallet \\
\hline Maleic anhydride & {$[\mathrm{mg}]$} & $\times$ & 5.88 \\
\hline Benzo[a]pyrene & {$[\mu \mathrm{g}]$} & 84.1 & 57.8 \\
\hline $\mathrm{Cd}$ & {$[\mathrm{mg}]$} & 32.7 & 26.8 \\
\hline $\mathrm{CO}$ & {$[\mathrm{g}]$} & 74.3 & 54.6 \\
\hline $\mathrm{CO}_{2}$ & {$[\mathrm{~kg}]$} & 73.1 & 42.0 \\
\hline $\mathrm{Cr}$ & {$[\mathrm{mg}]$} & 8.53 & 4.92 \\
\hline $\mathrm{Cu}$ & {$[\mathrm{mg}]$} & 45 & 28.6 \\
\hline Dimethenamide & {$[\mathrm{mg}]$} & $\times$ & 36.9 \\
\hline $\mathrm{Glyphosate}$ & {$[\mathrm{mg}]$} & $\times$ & 38.7 \\
\hline $\mathrm{H}_{2} \mathrm{~S}$ & {$[\mathrm{mg}]$} & 80.6 & 28.3 \\
\hline $\mathrm{HCl}$ & {$[\mathrm{g}]$} & 4.48 & 3.65 \\
\hline $\mathrm{HF}$ & {$[\mathrm{mg}]$} & 506 & 201.0 \\
\hline $\mathrm{Hg}$ & {$[\mathrm{mg}]$} & 1.48 & 0.68 \\
\hline $\mathrm{Methane}$ & {$[\mathrm{g}]$} & 150 & 79.4 \\
\hline $\mathrm{Mn}$ & {$[\mathrm{mg}]$} & 36.6 & 24.3 \\
\hline $\mathrm{N}_{2} \mathrm{O}$ & {$[\mathrm{g}]$} & 1.96 & 2.2 \\
\hline $\mathrm{NH}_{3}$ & {$[\mathrm{~g}]$} & 0.123 & 11.3 \\
\hline $\mathrm{Ni}^{\mathrm{N}}$ & {$[\mathrm{mg}]$} & 142 & 88.6 \\
\hline $\mathrm{NMHC}^{\mathrm{N}}$ & {$[\mathrm{g}]$} & 497 & 318 \\
\hline $\mathrm{NO}_{\mathrm{x}}$ & {$[\mathrm{g}]$} & 513 & 349 \\
\hline $\mathrm{P}$ & {$[\mathrm{mg}]$} & 5.19 & 2.27 \\
\hline $\mathrm{Particles}$ & {$[\mathrm{g}]$} & 57.5 & 35.1 \\
\hline $\mathrm{Pb}$ & {$[\mathrm{mg}]$} & 195 & 56.2 \\
\hline $\mathrm{Pendimethaline}$ & {$[\mathrm{mg}]$} & $\times$ & 34.6 \\
\hline $\mathrm{SO}_{\mathrm{x}}$ & {$[\mathrm{g}]$} & 289 & 163 \\
\hline $\mathrm{V}$ & {$[\mathrm{g}]$} & 1.16 & 0.731 \\
\hline $\mathrm{Zn}$ & & 512 & 375 \\
\hline & & \\
\hline & & & \\
\hline
\end{tabular}

Table 2. Comparison of environmental loads (expressed in Eco-indicator 99 points) of alternative pavements [9]; $n$ represents a given number of maintenance activities

\begin{tabular}{|l|c|c|c|c|c|}
\hline \multicolumn{1}{|c|}{ Slab type } & Erection & Maintenance & Disposal & Total & Relative load [\%] \\
\hline Steel reinforced pavement & 179000 & $n \cdot 13200$ & 6020 & 291000 & 100 \\
\hline FRP reinforced pavement 1 & 114000 & N/A & 7680 & 122000 & 44 \\
\hline FRP reinforced pavement 2 & 117000 & N/A & 7680 & 124000 & 45 \\
\hline FRP reinforced pavement 3 & 134000 & N/A & 9310 & 144000 & 52 \\
\hline
\end{tabular}

Table 3. Comparison of environmental impact data for three ship superstructures with different waste disposal scenarios [10]

\begin{tabular}{|l|c|c|c|c|c|c|c|}
\hline \multirow{2}{*}{ Impact categories } & \multicolumn{3}{|c|}{ Balsa core sandwich super structure } & \multicolumn{2}{c|}{ PVC sandwich foam super structure } & Steel super structure \\
\cline { 2 - 8 } & Landfill & Incineration & Recycle & Landfill & Incineration & Recycle & Recycle \\
\hline Global warming (in kg CO eq. $_{2}$ ) & 0.127 & 0.127 & 0.127 & 0.128 & 0.128 & 0.128 & 0.152 \\
\hline Acidification (in kg SO $\mathrm{SO}_{2}$ eq.) & 0.000943 & 0.000943 & 0.000943 & 0.000951 & 0.000951 & 0.000951 & 0.00113 \\
\hline Abiotic depletion (in kg Sb eq.) & 0.0111 & 0.0111 & 0.0111 & 0.0112 & 0.0112 & 0.0112 & 0.0133 \\
\hline
\end{tabular}


chemicals. The study found that environmental impacts during all phases of fabric production can be reduced with changes in the use of renewable/ recyclable crops, increased product life, optimization of water systems and reduced waste production.

Giudice et al. [12] described a new method of materials selection in the life-cycle design process by integrating mechanical and environmental performance criteria. Their method utilized a multi-objective analysis technique to show the application of the approach for material selection of a car brake disk. The considered decision parameters were cost, environmental impact, and mechanical performance. The candidate materials were grey cast iron BS 350 and F3K20S Duralcan (aluminum matrix composite). Limiting factors such as mechanical design thresholds, geometry constraints, and feasibility of manufacturing methods for each candidate material were accounted for. Next to formulating environmental impact indices for the problem, an original step was taken in their work to incorporate computer aided design tools (including finite element method/FEM) into the multi-objective decision model, thus avoiding the need for physical experiments in the early stages of decision-making. In fact, the use of FEM models in complex structural material selection problems automatically ensures the use of application-specific criteria values, which otherwise would have to be found through definition of performance indices as described in Section 1. For complex parts with nonlinear material and/or geometries, defining such indices analytically can be a very difficult task.

A multi-criteria decision matrix along with a grey relational solution method was developed by Chan and Tong [13] to choose the best materials for a vacuum cleaner dustbin. The candidate materials were analyzed with respect to their cost, impact on the environment and human health, and disposal methods. A weight (importance factor) was given to each criterion, but the weights could change depending on who makes the analysis (i.e., a subjective weighting method was adapted). Three types of materials were nominated: aluminum alloy (AL), acrylonitrile butadiene styrene (ABS) and polyurethane (PU). For the end-of-life (EOL) disposal stage, four strategies were taken into consideration: remanufacturing/reuse (REM), recycling (REC), incinera-
Table 4. The EOL grey relational grades for candidate materials of a vacuum cleaner dustbin [13]

\begin{tabular}{|c|c|c|}
\hline Ranking & EOL order pair & Grey relational grade \\
\hline 1 & ABS-REC & 0.7708 \\
\hline 2 & AL-REM & 0.6920 \\
\hline 3 & ABS-INC & 0.5083 \\
\hline 4 & ABS-LND & 0.5081 \\
\hline 5 & AL-REC 0 & 0.4863 \\
\hline 6 & PU-INC 0 & 0.3846 \\
\hline 7 & PU-LND & 0.3647 \\
\hline
\end{tabular}

tion with energy recovery (INC), and disposal to landfill (LND). Subsequently, a grey coefficient was calculated and assigned to each combination of material-disposal options (e.g., ABS with recycling). The coefficients (scores) made it possible for the decision-maker to rank the candidates as shown in Table 4. The higher the coefficients, the better the option in relation to the EOL treatment.

A systematic comparison of LCAs of compression moulded wood-fiber-reinforced polypropylene composite sheets with that of pure polypropylene is discussed by Xu et al. [14]. They introduced a new analysis index called 'material service density', which is defined as the volume of material satisfying a specific strength requirement. In contrast, for the cases where the volume of a part is fixed, they used the notion of 'volume functional unit'. Two sets of LCA were conducted on the wood-fiber-reinforced composites with 10,30, and 50\% levels of fiber (mass) contents and the pure polypropylene. It was concluded that when material service density is used as a functional index during decision-making, wood-fiber-reinforced composite demonstrates superior environmental friendliness compared to polypropylene. Authors also discussed that environmental loads of natural fiber reinforced composites can decrease with sufficient evidence when the use phase of the design is focused on. In other words, it is of utmost importance for material designers to note that the use of natural fibers in composite materials does not automatically make them 'sustainable/ environment friendly' unless the use phases (i.e., transportation) can justify that. It is the light density of natural fiber reinforced polymer products that makes them very attractive alternatives regarding their environmental impact during the use stage. If the material production phase is taken into account only, which often includes cultivation, pesticides and other types of chemical by-products, the envi- 
ronmental standing of natural fiber composites compared to their counterparts made of synthetic fibers and resins is not conclusive. The energy regain obtained during recycling phase of green composites also plays an important role in the LCA analysis.

\section{Recycling}

While at the design stage, decision-making models are considered as powerful mathematical tools to assess the performance of different existing composite options against more traditional material alternatives, from the reviews presented in Section 2 and related patents such as [15], it is clear that a significant research interest is currently on the development of green composites composed of natural fibers (such as wood, bagasse, rice straw, and pine fibers) and/or biodegradable polymers such as polyglycolic acid (PGA) and cellulosic plastics. Some of the main challenges in this area remains to be the high cost of production, moisture stability problems during storage and utilization, quality consistency in produced composites, and effective coupling agents between fibers and polymer [16, 17]. Further research is needed before these new genre of composites can fully replace current synthetic composite constituents. At the same time, improving recycling techniques of synthetic composites is a key factor to address environmental aspects of using these materials and also landfill use restrictions that are increasingly faced by different composite manufacturers. Recycling technologies for thermoset composites is extensively reviewed in the reference [18]. The major problem with recycling these materials is the existence of cross linked molecules in the polymer. Some reported recycling processes include pyrolysis, use of thermal fluidized bed, and grinding. The LCA and recycling techniques of thermoplastic composites such as PE, PP, PS and PVC, technical challenges along with their economic merits can be found in other studies such as $[19,20]$. The most commonly used technique is perhaps mechanical recycling, when compared to chemical, physicochemical or energy recovery recycling. In the mechanical method, plastics from industrial waste undergo sorting, shredding and washing processes to yield plastic flakes, pellets or powder that can be reused in the manufacturing of new products, e.g., via extrusion. It is shown that recy- cled composites can significantly reduce environmental impact during the materials acquisition and processing phases compared to conventional virgin thermoplastics [20].

Remark: It is worth adding that although over the past decade some of the recycling processes of synthetic composites along with the development of natural composites have proven to yield high amounts of recyclates and save significant environmental loads, there still seems to be a need for more imminent demand in market in order to achieve their cost effectiveness across composite sectors for mass production. The actual case studies such as [21] show that the recycling of composites would not be cost-effective for companies unless there are dramatic changes to recycling policies or cost of petroleum.

\section{An illustrative example on gear material selection:}

A new application of signal-to-noise

This case study is primarily intended to illustrate the application of MCDM by which concerns about multiple conflicting criteria can be formally addressed into an interdisciplinary material selection process. MCDM, also often referred to as multicriteria optimization, is particularly useful for the comparison of a finite set of different alternatives/ scenarios against a set of decision criteria [22]. Both qualitative and quantitative values, monotonic and non-monotonic criteria, design tolerances, along with both objective and subjective weighting factors from individual or group of decision makers can be incorporated into such solution methods.

Different types of MCDM models have been already employed in the past decade for material selection problems concerning mechanical properties, cost and manufacturing criteria; see [23] for a state-ofthe-art review.

In the early stage of a design, more general methods such as Ashbey's material selection charts can be used to identify a range of possible material solutions/candidates given an application. Alternatively screening methods, such those reviewed in [23], can be applied to shortlist a large pool/table of material candidates. In the simplest form, the screening process may involve defining a minimum/threshold value for each decision criteria. A candidate material is shortlisted only if it passes all 
the criteria thresholds. As such, all the screened candidates are considered feasible solutions, yet they should be ranked from top to bottom for a final decision at the end of the design process. For the latter ranking, MCDM methods such as the weighted sum method (WSM), TOPSIS, ELECTRE can be used [24]. No or little effort has been made to formally incorporate the above powerful decision making tools in material selection problems in the presence of LCA criteria. The selection techniques employed in the studies [12] and [13] can be indentified within this category of models.

To exemplify the application of MCDM in the intended case study, let us take two different gear material options along with their cost, thermal and mechanical performances, and environmental impacts. The given material options are pure polyethylene terephthalate (PET) and a composite made of $70 \%$ PET (i.e., with the weight fraction $\mu_{\mathrm{PET}}=$ $0.7)$ and $30 \%$ aluminum powder $\left(\mu_{\mathrm{Al}}=0.3\right)$. The

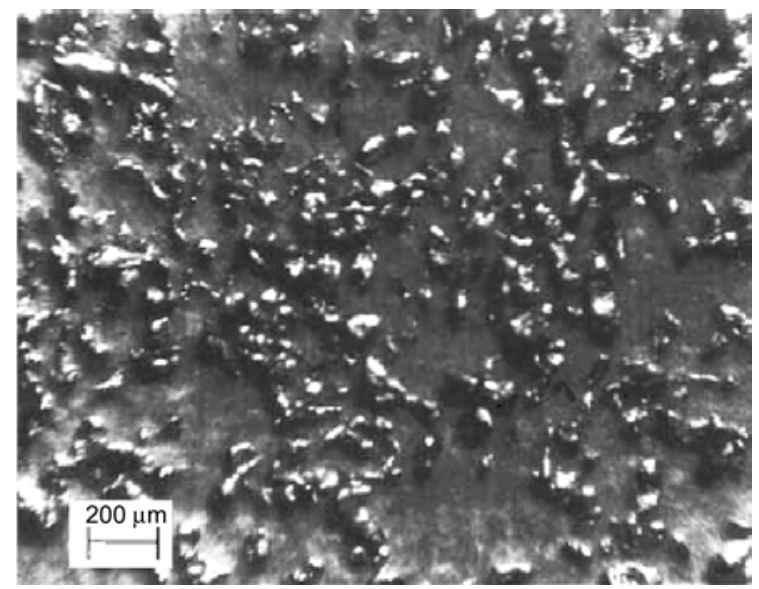

Figure 2. Sample micrograph of aluminum powder in a polymer matrix (Tavman, 1996)
PET/aluminum powder composite (Figure 2) is an example of the large variety of polymer-matrix/particle filling composites that are widely used in military and civil applications [25]. The material cost, thermal and mechanical properties of each alternative gear option are included in Table 5. Environmental impact of PET-Al gear is assessed by establishing a life cycle shown in Figure 3. Subsequently, using the GaBi 4 software, an LCA analysis was performed based on three stages of life cycle: material production, transportation, and disposal/recycling. In Figure 3, the composite gear manufacturing facility receives PET ( $70 \%$ by weight) and aluminum ( $30 \%$ by weight) as raw materials which weigh a total of $1 \mathrm{lb}$. Only $50 \%(0.35 \mathrm{lb})$ of the total PET $(0.70 \mathrm{lb})$ is new PET while the remaining portion $(0.35 \mathrm{lb})$ is the recycled material according to the recyclable fraction in Table 5. Similarly, only $15 \%(0.045 \mathrm{lb})$ of the total aluminum $(0.30 \mathrm{lb})$ is new aluminum as the remaining weight $(0.255 \mathrm{lb})$ is comprised of the recycled material based on $85 \%$ recyclable fraction indicated for aluminum. In Figure 3 , in addition to manufacturing, two separate disposal options are considered. Upon manufacturing and consumer use, $50 \%$ of the non-recyclable portions of the PET $(0.175 \mathrm{lb})$ and aluminum $(0.0225 \mathrm{lb})$, in other words the 'solid waste' generated, are assumed to be incinerated while the remaining waste fractions $(50 \%)$ are directed to a nearby landfill. Similarly, the LCA analysis was repeated for the pure PET gear option.

The obtained environmental criteria values from LCA are added in Table 5 next to the mechanical and cost criteria. It is assumed that the manufactur-

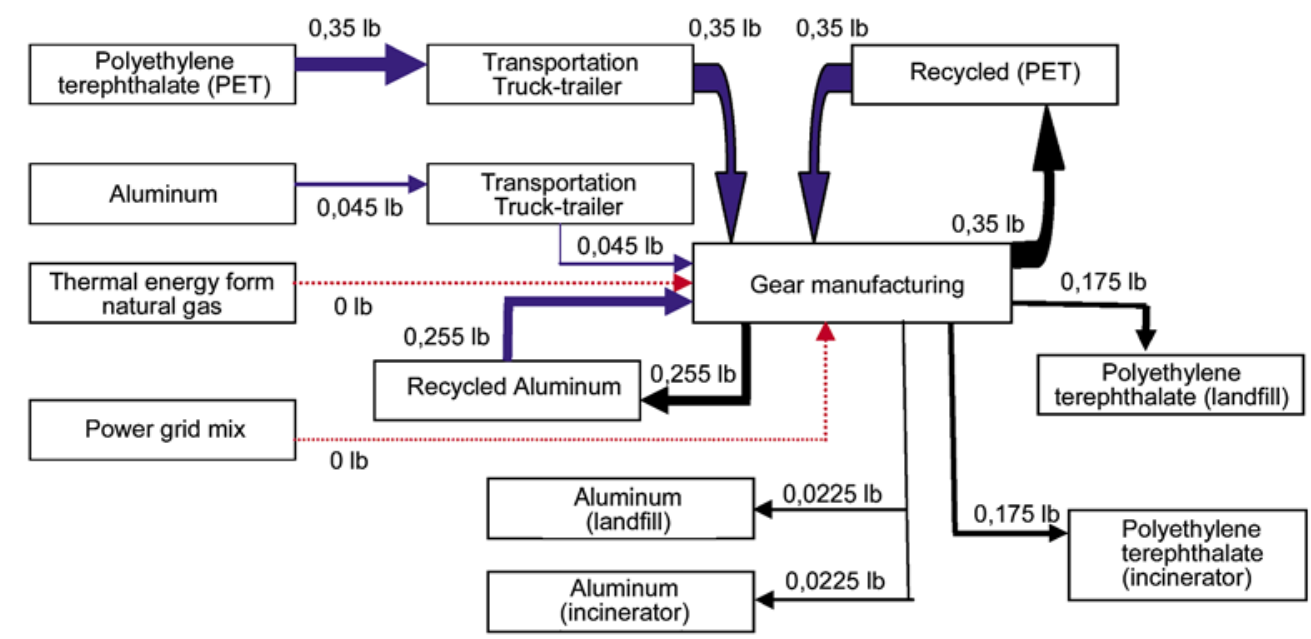

Figure 3. A basic life cycle of the PET-Al composite gear 
ing cost and energy of the two material candidates are comparable (at least for a low-scale production). The negative signs in the last column of Table 5 indicate that the corresponding criteria are defined as cost-type (i.e., the lower the better) by the designer. The composite mechanical properties needed to be estimated from the volume fraction of its constituents (i.e., PET and Al). To this end, a simple rule of mixture was used as Equation (1):

$P_{\text {composite }}=v_{\mathrm{Al}} \cdot P_{\mathrm{Al}}+v_{\mathrm{PET}} \cdot P_{\mathrm{PET}}$

where $P$ represents the property to be obtained in relation to the percentage compositions of the constituent materials $v_{\mathrm{Al}}$ and $v_{\mathrm{PET}}$ are the volume fractions of the composite constituents and can be related to their weight fractions based on Equations (2) and (3) [26]:

$\mu_{\mathrm{Al}}=\frac{\rho_{\mathrm{Al}}}{\rho_{\text {composite }}} v_{\mathrm{Al}}$

$\mu_{\mathrm{PET}}=\frac{\rho_{\mathrm{PET}}}{\rho_{\text {composite }}} v_{\mathrm{PET}}$

where $\rho_{\text {composite }}$ is the density of the composite and is related to the density of the constituents as Equation (4):

$\frac{1}{\rho_{\text {composite }}}=\frac{\mu_{\mathrm{Al}}}{\rho_{\mathrm{Al}}}+\frac{\mu_{\mathrm{PET}}}{\rho_{\mathrm{PET}}}$

For calculating the effective longitudinal thermal expansion coefficient of the composite, $\alpha_{\text {composite, }}$

Table 5. Multi-disciplinary property values of candidate materials in the present case study

\begin{tabular}{|c|c|c|c|c|c|c|c|c|c|c|c|}
\hline Category & Properties & $\begin{array}{c}\text { Al } \\
\text { (Min) }\end{array}$ & $\begin{array}{c}\text { Al } \\
(\text { Max })\end{array}$ & $\begin{array}{c}\text { PET } \\
\text { (Min) }\end{array}$ & $\begin{array}{l}\text { PET } \\
\text { (Max) }\end{array}$ & $\begin{array}{c}\text { Al } \\
\text { (Ave) }\end{array}$ & $\begin{array}{l}\text { PET } \\
\text { gear } \\
\text { (Ave) }\end{array}$ & $\begin{array}{c}\text { Composite } \\
\text { gear } \\
\text { (Ave) }\end{array}$ & \begin{tabular}{|l|} 
Normalized \\
PET \\
properties
\end{tabular} & \begin{tabular}{|c|} 
Normalized \\
composite \\
properties
\end{tabular} & \pm Factor \\
\hline Cost & Price [USD/lb] & 0.6453 & 1.046 & 0.835 & 0.919 & 0.846 & $0.4383^{*}$ & $0.3449^{* *}$ & -1 & -0.7868 & - \\
\hline \multirow{10}{*}{ 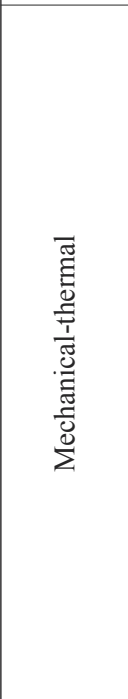 } & Density $\left[\mathrm{lb} / \mathrm{in}^{3}\right]$ & 0.0964 & 0.0986 & 0.047 & 0.051 & 0.098 & 0.0486 & 0.0572 & -0.8494 & -1.0000 & - \\
\hline & $\begin{array}{l}\text { Young's modulus } \\
{\left[10^{6} \mathrm{psi}\right]}\end{array}$ & 10.1 & 10.44 & 0.4 & 0.601 & 10.27 & 0.5004 & 2.2191 & 0.2255 & 1.0000 & + \\
\hline & Elastic limit [ksi] & 4.134 & 4.569 & 8.195 & 9.036 & 4.352 & 8.6155 & 7.8653 & 1 & 0.9129 & + \\
\hline & $\begin{array}{l}\text { Tensile strength } \\
{[\mathrm{ksi}]}\end{array}$ & 11.02 & 12.18 & 7.005 & 10.5 & 11.6 & 8.7525 & 9.2535 & 0.9459 & 1.0000 & + \\
\hline & $\begin{array}{l}\text { Hardness rockwell } \\
{[\mathrm{R}]}\end{array}$ & 24.5 & 25.5 & 17 & 18.7 & 25 & 17.85 & 19.1079 & 0.9342 & 1.0000 & + \\
\hline & $\begin{array}{l}\text { Endurance limit } \\
{[\mathrm{ksi}]}\end{array}$ & 3.046 & 3.336 & 2.802 & 4.2 & 3.191 & 3.501 & 3.4465 & 1 & 0.9844 & + \\
\hline & $\begin{array}{l}\text { Fracture toughness } \\
{\left[\mathrm{ksi} \cdot \mathrm{in}^{1 / 2}\right]}\end{array}$ & 27.3 & 31.85 & 4.323 & 4.778 & 29.58 & 4.5505 & 8.9530 & 0.5083 & 1.0000 & + \\
\hline & $\begin{array}{l}\text { Thermal conductiv- } \\
\text { ity }\left[\mathrm{BTU} \cdot \mathrm{ft} / \mathrm{h} \cdot \mathrm{ft}^{2} \cdot \mathrm{F}\right]\end{array}$ & 118.4 & 123.1 & 0.08 & 0.087 & 120.8 & 0.0835 & 21.3119 & 0.0039 & 1.0000 & + \\
\hline & $\begin{array}{l}\text { Thermal expansion } \\
{[\mu \text { strain } / \mathrm{F}]}\end{array}$ & 12.33 & 13 & 63.7 & 66.3 & 12.67 & 65 & 22.3901 & -1 & -0.3445 & - \\
\hline & $\begin{array}{l}\text { Max service temp } \\
{[\mathrm{F}]}\end{array}$ & 266 & 392 & 152.6 & 188.6 & 329 & 170.6 & 198.4667 & 0.8596 & 1.0000 & + \\
\hline \multirow{8}{*}{ 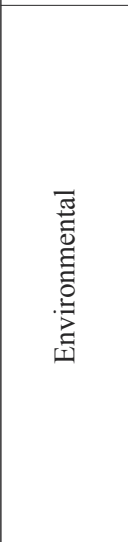 } & $\begin{array}{l}\text { Production energy } \\
{[\mathrm{kcal} / \mathrm{lb}]}\end{array}$ & 20500 & 22600 & 8624 & 9534 & 21560 & 9079 & 12823 & -0.7080 & -1 & - \\
\hline & $\begin{array}{l}\mathrm{CO}_{2} \text { creation } \\
{[\mathrm{lb} / \mathrm{lb}]}\end{array}$ & 9.03 & 9.98 & 2.21 & 2.45 & 9.505 & 2.33 & 4.4825 & -0.5198 & -1 & - \\
\hline & Recyclable fraction & 0.8 & 0.9 & 0.45 & 0.55 & 0.85 & 0.5 & 0.605 & 0.8264 & 1 & + \\
\hline & Resources [lb/lb] & & & & & & 247.91 & 247.93 & -0.9999 & -1 & - \\
\hline & \begin{tabular}{|l} 
Emission to air \\
{$[\mathrm{lb} / \mathrm{lb}]$}
\end{tabular} & & & & & & 240.82 & 240.75 & -1 & -0.9997 & - \\
\hline & $\begin{array}{l}\text { Emission to fresh } \\
\text { water }[1 \mathrm{~b} / \mathrm{lb}] \\
\end{array}$ & & & & & & 0.3375 & 0.32 & -1 & -0.9483 & - \\
\hline & $\begin{array}{l}\text { Emission to sea } \\
\text { water [lb/lb] }\end{array}$ & & & & & & 0.0101 & 0.0101 & -1 & -1 & - \\
\hline & $\begin{array}{l}\text { Emission to indus- } \\
\text { trial soil [lb/lb] }\end{array}$ & & & & & & 0.0001 & 0.0001 & -1 & -0.9663 & - \\
\hline
\end{tabular}

${ }^{*}$ For $1 \mathrm{lb}$ of the PET gear, $50 \%$ of the material comes from the recycled fraction, thus the net cost is reduced by $50 \%$.

${ }^{* *}$ For $1 \mathrm{lb}$ of the composite gear, $50 \%$ of PET and $85 \%$ of $\mathrm{Al}$ come from the corresponding recycled fractions, thus the estimated cost is adjusted. 
the thermoelastic extremum principle yields [26] (Equation (5)):

$$
\begin{aligned}
\alpha_{\text {composite }} & =\frac{E_{\mathrm{Al}}}{E_{\text {composite }}}\left(v_{\mathrm{Al}} \cdot \alpha_{\mathrm{Al}}\right)+ \\
& +\frac{E_{\mathrm{PET}}}{E_{\text {composite }}}\left(v_{\mathrm{PET}} \cdot \alpha_{\mathrm{PET}}\right)
\end{aligned}
$$

where $E_{\mathrm{AL}}$, PET, composite denotes, respectively, the Young's modulus of Al, PET and the composite (Table 1). Finally, for the composite environmental factors, a similar rule of mixture as in Equation (1) was employed by using the weight fractions in order to be consistent with the Eco-indicator 99 values.

Next, properties within each category of cost, environmental impact, thermal/mechanical performance are normalized using the two average values in each row (one for PET and one for the composite). The normalization is necessary since different properties are of different units. To this end, each criterion value is divided by the maximum of the two material values. For example, for the elastic limit criterion, the (average) PET value is $8.6155 \mathrm{ksi}$ and the composite value is $7.8653 \mathrm{ksi}$. The normalized values, respectively, are calculated as $8.6155 / 8.6155$ and 7.8653/8.6155. For cost-type criteria, after the above normalization, the values are multiplied by ' -1 ' as seen in the grey cell (i.e., the final decision matrix) in Table 5.

From the normalized decision matrix, where for all values the higher-the-better, one can notice that each material option is superior to the other under some particular criteria, but lacking under the rest of criteria. To aggregate all the conflicting criteria values into one overall score, the well-known weighted sum method (WSM) was used for each material; $i=1,2$ (Equation (6)) [22]:

$$
\begin{aligned}
\text { Score }_{\mathrm{i}} & =\sum \omega_{(\text {cost })} \cdot N P_{\mathrm{j}(\text { cost })} \\
& +\sum \omega_{(\text {Mechanical-Thermal }} \cdot N P_{\mathrm{j} \text { (Mechanical-Thermal) }}+ \\
& +\sum \omega_{(\text {Environmental) }} \cdot N P_{\mathrm{j}(\text { Environmental) }}
\end{aligned}
$$

where $N P_{\mathrm{j}}$ refer to the normalized values and $\omega$ values are the weights of the three categories of criteria for the decision maker/designer. For instance, if environmental impact is a major concern in a project, the weight of all criteria under this category
Table 6. Initial weights of different criteria categories based on the designer/decision-maker's viewpoint

\begin{tabular}{|l|c|c|c|}
\hline \multirow{2}{*}{} & \multicolumn{3}{|c|}{ Category } \\
\cline { 2 - 4 } & Cost & Mechanical/Thermal & Environmental \\
\hline Weight & 0.25 & 0.25 & 0.5 \\
\hline
\end{tabular}

Table 7. Scores for the PET and composite options using the weights in Table 6

\begin{tabular}{|l|c|c|}
\hline Criteria categories & Materials & Composite \\
\hline Cost & -0.250 & -0.196 \\
\hline Mechanical/Thermal & 0.907 & 1.638 \\
\hline Environmental & -2.700 & -2.957 \\
\hline WSM total score & -2.043 & -1.515 \\
\hline
\end{tabular}

would have higher values than the rest of criteria. In the current example, a set of initial weights was assumed as shown in Table 6. Based on these weights and the equation above, the sub-total and the total score of each material are calculated in Table 7. The overall score of the composite suggests that it should be ranked/preferred over the pure PET option. Also, for both materials, it is clear from the sub-criteria scores that the (negative) environmental load is the highest compared to the mechanical/thermal and cost performance values.

\subsection{Sensitivity analysis}

After an initial estimation of weights, it is often the case that the designer/decision maker (DM) would be interested to know how the trade-off between criteria categories plays a role on the final material ranking (sensitivity analysis). To this end, it would suffice that the DM simply changes the relative weight values $(\omega)$ between the criteria groups and recalculates the scores. Different weight combinations yield different material recommendations as summarized in Figures 4-6. Since here we have three categories of criteria, for better visualization purposes, a mapping from three-dimensional Pareto space to the two-dimensional space has been used by fixing the level of one weight at a time and plotting the effect of the variation of the other two on the material scores. Also note that at each point, the sum of weights (cost, environmental, and mechanical-thermal) is the unity. For instance, in Figure 4a, given the cost weight of $10 \%$, the summation of mechanical-thermal and environmental criteria should be $90 \%$. That means, e.g., for the two points 

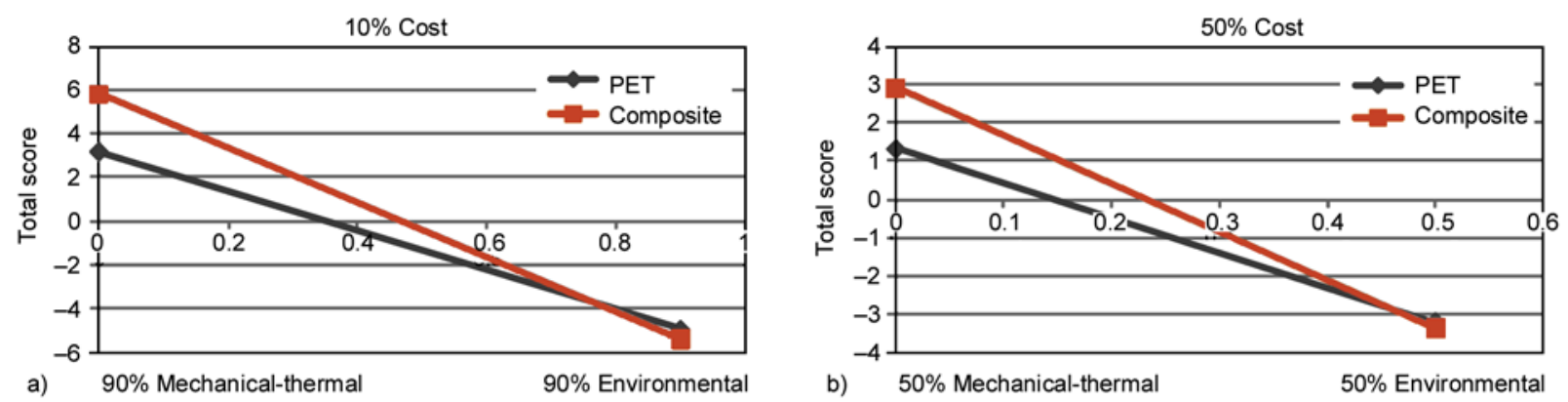

Figure 4. The trade-off between the (thermo) mechanical and environmental criteria at different fixed cost criterion weights
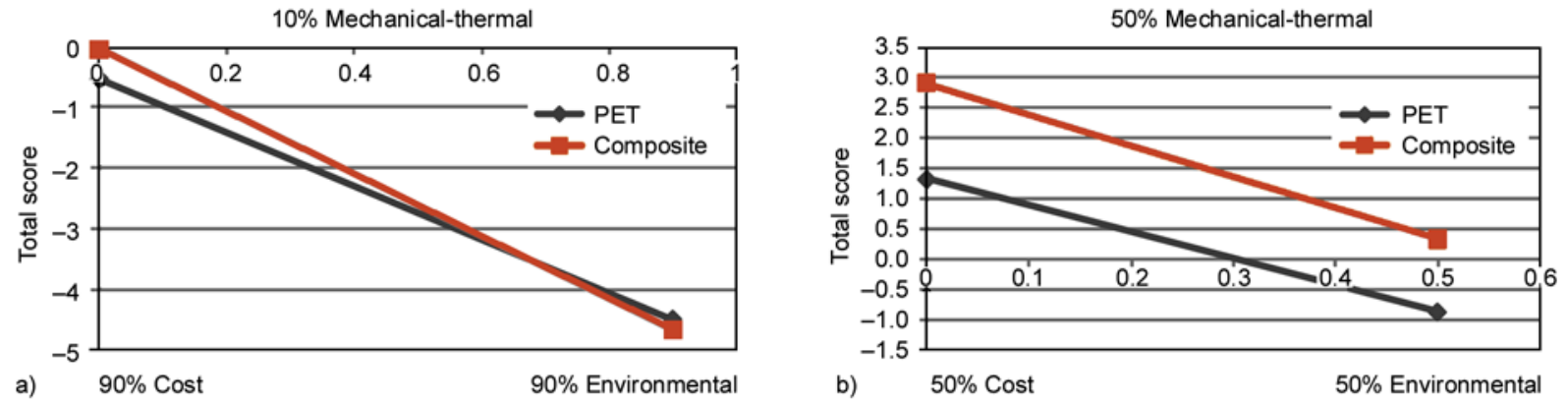

Figure 5. The trade-off between the cost and environmental criteria at different fixed (thermo) mechanical criteria weights
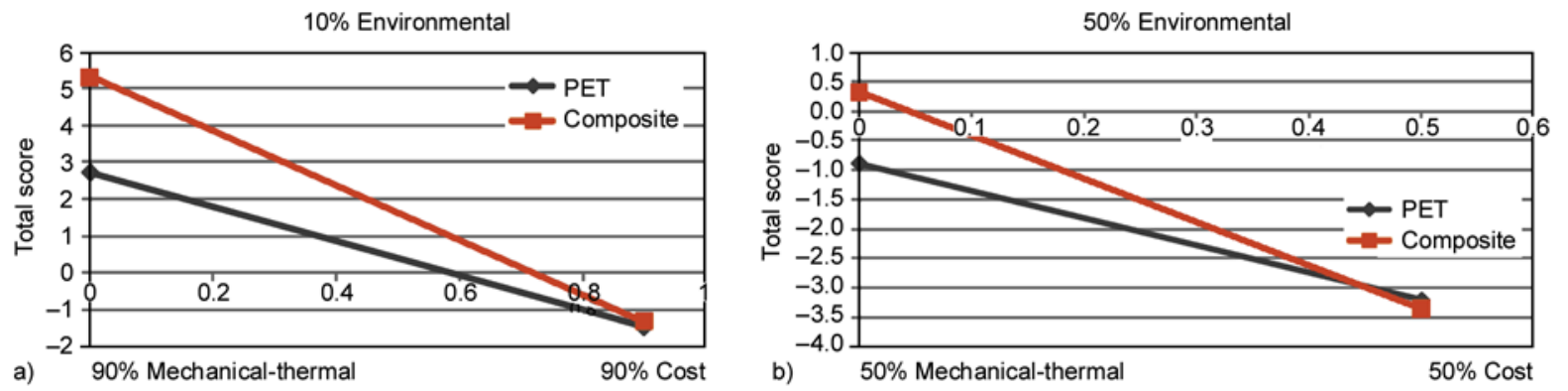

Figure 6. The trade-off between the cost and (thermo) mechanical criteria at different fixed environmental criteria weights

on the left corner of the plot, the mechanical-thermal criteria weight is $90 \%$ and the environmental $0 \%$.

From Figure $4 \mathrm{~b}$ one can conclude that at a high weight of cost $(\sim 50 \%)$, the composite material outperforms PET regardless of their differences in the mechanical-thermal performance and environmental impact values due to higher recyclability percentage. From Figure 4a, however, one notices that when the cost weight is low $(10 \%)$, there is a 'break even' point ( $\sim 15 \%$ mechanical-thermal, i.e., $75 \%$ environmental) where the ranking of the two material swaps. A similar break-even point can be noticed in Figure 5a regarding the cost and environmental criteria. The indication from this figure along with Table 7 is that a low cost can be achieved at the expense of higher environmental impact and vice versa. For higher mechanical-thermal weights as in
Figure $5 \mathrm{~b}$, the composite is noticeably preferred over PET. Finally, from Figure 6, it is seen that the composite can outperform the PET alternative with no break-even point for lower environmental weights (up to $\sim 35 \%$ ).

\subsection{A signal-to-noise concept}

The WSM method in Equation (6) is perhaps the most common method among MCDM models in practical applications [27]. It is important, however, to understand that this method is compensatory in that the sub-scores of criteria (after normalization and weighting) are added together to find a total score. As such, the decision maker/designer implicitly agrees that a low value of one criterion can be compensated by a high value of another criterion in the final decision-making. This should be true most of the time for the type of applications outlined in 
this paper (selection of optimal composite product), but there may be cases where the designer would like to limit this direct compensation among selection criteria by means of their variability. To this end, here we use a new concept based on a signalto-noise $(\mathrm{S} / \mathrm{N})$ ratio for material selection.

The definition of $\mathrm{S} / \mathrm{N}$ may be based on the inverse of well-known 'coefficient of variation (CV)' in statistics. CV, also known as unitized risk, is a normalized measure of dispersion which is found by dividing the standard deviation of a sample $\sigma$ to its mean $\mu$. Thus, the $\mathrm{S} / \mathrm{N}$ score may be defined as $\mu / \sigma$. To understand this in the MCDM context, let us recall the upper-level decision matrix of Table 7, where sub-criteria within each category (environmental, mechanical/thermal, and cost) have been aggregated, but the designer may hesitate to sum the values between groups of different criteria. To formalize this non-compensatory ranking preference, for each material column in Table 7 one can find the mean $\mu$ and divide it by the standard deviation of the column $\sigma$. For instance, for PET (Equation (7)):

$$
\begin{aligned}
\mathrm{S} / \mathrm{N}_{(\mathrm{PET})} & =\frac{\text { Average }(-0.250,0.907,-2.700)}{\operatorname{STD}(-0.250,0.907,-2.700)}= \\
& =-0.369
\end{aligned}
$$

Similarly, for the composite option we find $\mathrm{S} / \mathrm{N}_{\text {(composite) }}=-0.218$. A larger signal to noise ratio should be preferred. In essence this means, one would like to chose a material that on average has a high score $(\mu)$ over all criteria but at the same time has a low variation $(\sigma)$ among different categories of criteria. That is, ideally, the chosen material should be good in all criteria. Given the above scores for the two alternative materials in the present case study, the composite option outperforms the pure plastic material with the $\mathrm{S} / \mathrm{N}$ non-compensatory approach.

\section{Conclusions}

In today's integrated design processes for composite products, it is necessary to explore optimal design options by simultaneously analyzing material properties in a multitude of disciplines (mechanical, cost, environmental, etc). Next to the existing selection tools [28], MCDM models can provide the ability to formulate and systematically compare different alternatives against large sets of design criteria, thus giving engineers a versatile tool to tackle complex decision-making tasks. To show an application of a well-known MCDM method (namely the WSM) in a relatively large-scale decision space (with one cost, seven environmental, and eleven mechanical/thermal attributes), an illustrative example was presented in a plastic gear material selection problem. A pure PET gear was compared to a composite PET/aluminum-powder alternative. The results showed a higher total score for the composite. It was also shown that the method can be employed to explore criteria trade-offs and decision break-even points by varying the designer's weights over different criteria categories. Similar MCDM models can be used by other practitioners to mathematically study the benefits gained and losses endured during material development, replacement or selection of new products. In doing so, however, next to basic MCDM models such as WSM, it may be worth investigating the application of more advanced methods that can include uncertainties both in material datasets as well as designers/decision makers' opinions over criteria weights (see, e.g. [29] for an application of ELECTRE III and revised Simos' methods). Advanced MCDM methods under uncertain/incomplete data can be particularly important for the LCA analysis of composites since inventory databases in the commercial LCA packages are still not inclusive and modeling assumptions normally need to be made (as is the case in several reported LCA studies including those reviewed in this article). The notation of compensation and non-compensations may be accounted for during multi-disciplinary material selection problems. An application of a signal-to-noise concept was recommended in the present case study by dividing the average score of each alternative over a dispersion measure showing the non-uniformity of the given material performance over different criteria categories. Finally, it should be pointed out that for more practical, real-world design scenarios, the analysis of material candidates' disposal options as well as their recyclable percentages need to be aligned with waste management codes and regulations of both manufacturers and local authorities. Accordingly, next to the cost of raw material, the inclusion of production and disposal costs can be vital for a successful multiple criteria material selection process. 


\section{Acknowledgements}

Financial support from the Natural Sciences and Engineering Research Council (NSERC) of Canada as well as the UBC's Work-Learn Program is acknowledged. The authors are also grateful to the anonymous referees for their constructive comments and suggestions.

\section{References}

[1] Ashby M.: Materials selection in mechanical design. Butterworth-Heinemann, Burlington (1999).

[2] Soutis C.: Fibre reinforced composites in aircraft construction. Progress in Aerospace Sciences, 41, 143151 (2005)

DOI: 10.1016/j.paerosci.2005.02.004

[3] Lua J.: Thermal-mechanical cell model for unbalanced plain weave woven fabric composites. Composites Part A: Applied Science and Manufacturing, 38. 1019-1037 (2007).

DOI: $10.1016 /$ j.compositesa.2006.06.023

[4] Scelsi L., Bonner M., Hodzic A., Soutis C., Wilson C., Scaife R., Ridgway K.: Potential emissions savings of lightweight composite aircraft components evaluated through life cycle assessment. Express Polymer Letters, 5, 209-217 (2011).

DOI: $10.3144 /$ expresspolymlett.2011.20

[5] Holbery J., Houston D.: Natural-fiber-reinforced polymer composites in automotive applications. Journal of the Minerals, Metals and Materials Society, 58, 80-86 (2006).

DOI: $10.1007 / \mathrm{s} 11837-006-0234-2$

[6] Shibata M., Oyamada S., Kobayashi S., Yaginuma D.: Mechanical properties and biodegradability of green composites based on biodegradable polyesters and lyocell fabric. Journal of Applied Polymer Science, 92, 3857-3863 (2004).

DOI: $10.1002 / a p p .20405$

[7] Netravali A. N., Huang X., Mizuta K.: Advanced 'green' composites. Advanced Composite Materials, 16, 269-282 (2007).

DOI: $10.1163 / 156855107782325230$

[8] Corbière-Nicollier T., Gfeller Laban B., Lundquist L., Leterrier Y., Månson J.: Jolliet O.: Life cycle assessment of biofibres replacing glass fibres as reinforcement in plastics. Resources, Conservation and Recycling, 33, 267-287 (2001). DOI: $10.1016 / \mathrm{S} 0921-3449(01) 00089-1$

[9] Katz A.: Environmental impact of steel and fiber-reinforced polymer reinforced pavements. Journal of Composites for Construction, 8, 481-488 (2004). DOI: 10.1061/(ASCE) 1090-0268(2004)8:6(481)

[10] Umair S.: Environmental impacts of fiber composite materials. MSc Thesis, Royal Institute of Technology, Stockholm (2006).
[11] Centre for Design at RMIT University: Aiming for sustainable product development. Technical report (2001).

[12] Giudice F., La Rosa G., Risitano A.: Materials selection in the life-cycle design process: A method to integrate mechanical and environmental performances in optimal choice. Materials and Design, 26, 9-20 (2005). DOI: $10.1016 /$ j.matdes.2004.04.006

[13] Chan J. W. K., Tong T. K. L.: Multi-criteria material selections and end-of-life product strategy: Grey relational analysis approach. Materials and Design, 28, 1539-1546 (2007).

DOI: $10.1016 / \mathrm{j}$. matdes.2006.02.016

[14] Xu X., Jayaraman K., Morin C., Pecqueux N.: Life cycle assessment of wood-fibre-reinforced polypropylene composites. Journal of Materials Processing Technology, 198, 168-177 (2008). DOI: 10.1016/j.jmatprotec.2007.06.087

[15] Turnlund T. H.: Biodegradable mesh and film stent. U.S. Patent 5766710, USA (1998).

[16] Mohanty A. K., Misra M., Drzal L. T.: Sustainable biocomposites from renewable resources: Opportunities and challenges in the green materials world. Journal of Polymers and the Environment, 10, 19-26 (2002). DOI: 10.1023/A:1021013921916

[17] Xu Y., Wu Q., Lei Y., Yao F., Zhang Q.: Natural fiber reinforced poly(vinyl chloride) composites: Effect of fiber type and impact modifier. Journal of Polymers and the Environment, 16, 250-257 (2008). DOI: $10.1007 / \mathrm{s} 10924-008-0113-8$

[18] Pickering S. J.: Recycling technologies for thermoset composite materials - Current status. Composites Part A: Applied Science and Manufacturing, 37, 12061215 (2006). DOI: 10.1016/j.compositesa.2005.05.030

[19] Gowayed Y. A., Vaidyanathan R., El-Halwagi M.: Synthesis of composite materials from waste fabrics and plastics. Journal of Elastomers and Plastics, 27, 7890 (1995). DOI: $10.1177 / 009524439502700106$

[20] Vidal R., Martínez P., Garraín D.: Life cycle assessment of composite materials made of recycled thermoplastics combined with rice husks and cotton linters. International Journal of Life Cycle Assessment, 14, 73-82 (2008). DOI: $10.1007 / \mathrm{s} 11367-008-0043-7$

[21] Duval D., MacLean H. L.: The role of product information in automotive plastics recycling: A financial and life cycle assessment. Journal of Cleaner Production, 15, 1158-1168 (2007). DOI: $10.1016 /$ j.jclepro.2006.05.030

[22] Sen P., Yang J-B.: Multiple criteria decision support in engineering design. Springer, New York (1998). 
[23] Jahan A., Ismail M. Y., Sapuan S. M., Mustapha F.: Material screening and choosing methods - A review. Materials and Design, 31, 696-705 (2010).

DOI: $10.1016 /$ j.matdes.2009.08.013

[24] Milani A. S., Shanian A.: Gear material selection with uncertain and incomplete data. Material performance indices and decision aid model. International Journal of Mechanics and Materials in Design, 3, 209-222 (2006).

DOI: $10.1007 / \mathrm{s} 10999-007-9024-4$

[25] Tavman I. H.: Thermal and mechanical properties of aluminum powder-filled high-density polyethylene composites. Journal of Applied Polymer Science, 62, 2161-2167 (1996).

DOI: $10.1002 /($ SICI)1097-4628(19961219)62:12<2161 ::AID-APP19>3.0.CO;2-8
[26] Kaw A. K.: Mechanics of composite materials. CRC Press, Boca Raton (2005).

[27] Triantaphyllou E.: Multi-criteria decision making methods: A comparative study. Kluwer, New York (2000).

[28] Ashby M. F., Bréchet Y. J. M., Cebona D., Salvoc L.: Selection strategies for materials and processes. Materials and Design, 25, 51-67 (2004).

DOI: 10.1016/S0261-3069(03)00159-6

[29] Shanian A., Milani A. S., Carson C., Abeyaratne R. C.: A new application of ELECTRE III and revised Simos' procedure for group material selection under weighting uncertainty. Knowledge-Based Systems, 21, 709720 (2008).

DOI: $10.1016 / \mathrm{j}$. knosys.2008.03.028 